\title{
Modelo de Gestión Territorial utilizado en la reconstrucción post terremoto y tsunami del 27-F en Chile
}

\author{
Experiencias de asociatividad público - privado en el Plan Maestro de Duao, lloca y La Pesca
}

González González, Luis Eduardo ${ }^{1}$

Arquitecto (Universidad de Valparaíso) y Magister en Hábitat Residencial (Universidad de Chile), Santiago, Chile, gonzalezgleduardo@gmail.com

\begin{abstract}
Resumen
En Chile, el terremoto y tsunami ocurridos el 27 de Febrero del año 2010, intensidad $8,8^{\circ}$ en la escala de Richter, dejaron en absoluta evidencia la necesidad de reconstruir planificadamente pequeñas localidades y caletas pesqueras ubicadas en la costa de la zona central del país, área donde la catástrofe generó los mayores daños físicos, sociales y económicos. Por este motivo, desde el año 2010 en adelante, el Estado de Chile puso en marcha una serie de adyacencias creativas que han buscado alcanzar un diseño urbano sostenible en todos los centros urbanos que fueron devastados a causa, principalmente, del tsunami.

El propósito Estatal se materializó a través de Planes Maestros de Reconstrucción Territorial, cuyo objetivo fue articular equipos multidisciplinarios para lograr la implementación de planes de reconstrucción integrales e innovadores en su modelo de gestión y simultáneamente, mediante la sumatoria de micro-estrategias urbanas, desarrollar imágenes de un futuro posible en aquellos poblados.

A partir de la experiencia chilena, se aborda como caso estudio el Plan de Reconstrucción Estratégico Sustentable, comúnmente conocido como PRES, de las localidades de Duao, lloca y La Pesca, ubicadas en la Región del Maule. Mediante este caso se reflejan éxitos y desaciertos de la asociatividad entre entidades públicas e instituciones privadas en la planificación territorial, en un contexto de emergencia post desastre natural.
\end{abstract}

Además, el resultado esperado es evidenciar el rol protagónico asumido por actores privados en la planificación territorial chilena en un contexto de emergencia, en el momento en que el Estado baja las barreras normativas.

En términos metodológicos, la investigación se desarrolla mediante lo que Jacques Derrida denominó Deconstrucción, es decir, la descomposición de los diferentes elementos teóricos que componen el tema, para analizarlos separadamente y para abordarlos posteriormente desde una perspectiva global.

Palabras clave: Reconstrucción, Planes Maestros, Catástrofe, Asociatividad.

\begin{abstract}
The Chilean earthquake and tsunami on February 27 th 2010 , which had an intensity of $8.8^{\circ}$ Richter it was a phenomenon that made more than evident the Chilean necessity of a coastline planning, namely in villages and coves located in central region of the country. Exactly in this region the catastrophe was where it made the major physical, social and economic damage. For these reasons, from 2010 onwards, the Chilean Government began to develop a group of creatives adjacencies that had as target to make a sustainable urban design in all the urban places that were destroyed by tsunami.

The Government purpose was materialised by Territorial Reconstruction Master Plans, which took the responsibility of articular multidisciplinary teams and thus to achieve the reconstruction plan implementation through the sumatory of micro urban strategies for these villages.

In this research the case of study is the Sustainable Strategic Reconstruction Plan (PRES due to its initials in spanish) of Duao, lloca and La Pesca, located in Maule Region. This case shows success and mistakes of the public and private associativity in the urban development within an emergency context post natural disaster.
\end{abstract}

Besides, the result of this research make evident the protagonist role that private institutions assume in emergency context, because in this time the Government come down suddenly the normative obstacle.

The methodology is through the deconstruction of each part of the theoretical contents.

Key words: Reconstruction, Master Plans, Catastrophe, Associativity. 
Innovación e Investigación en Arquitectura y Territorio. Departamento de Expresión Gráfica y Cartografía. Arquitectura. Escuela Politécnica Superior. Universidad de Alicante. №3 julio 2015

\section{Contextualización: El terremoto y tsunami del 27-F del año 2010}

La presente investigación indaga en torno a los planes de reconstrucción ${ }^{1}$ territorial gestados en Chile durante el año 2010 luego de sucedido el terremoto y tsunami el 27 de febrero de aquel año, en adelante 27-F, el cual afectó desde la Región de Valparaíso en el norte hasta la Región de la Araucanía en el sur. Dicha zona concentra aproximadamente al $80 \%$ de la población nacional y tuvo pérdidas en la infraestructura básica del país estimadas en más de US\$30.000 millones (Lagarraña y Herrera, 2010). Además, en materia de vivienda ocasionó un total de 220.000 familias afectadas (Plan Chile Unido Reconstruye Mejor, 2010).

Para contextualizar adecuadamente el escenario en que se han desarrollado las iniciativas Estatales de reconstrucción hoy día vigentes, es necesario revisar las tendencias que han orientado las políticas públicas en Chile durante su historia reciente y particularmente aquellas vinculadas con la gestión territorial. Dicha materia en el país ha sido abordada desde dos enfoques en extremo opuestos y que a continuación se enuncian.

En primer término, durante la primera parte del siglo XX y de acuerdo con Lawner (2010) se actuó desde un enfoque de Estado Benefactor entre los terremotos de 1905 a 1971, donde es el Estado quien se encarga de planificar, desarrollar y ejecutar iniciativas en pro de la ciudadanía. Luego, durante el Gobierno Militar a consecuencia del terremoto de 1985, el Estado realiza un cambio radical en su gestión territorial, de acuerdo con Tapia (2003), acercándose al mercado neoliberal, incidiendo éste directamente en las políticas públicas (Moulian, 1997), proceso en que la ciudad es vista como un producto comercial. Esta es una vertiente que con el paso del tiempo se ha transformado paulatinamente pero ha mantenido su esencia. A consecuencia de este último enfoque de políticas públicas, hoy en día el Estado establece las bases para la participación de actores externos, bajo la premisa de una libre competencia (Imilan y González, 2013).

Un reflejo de esta actual forma de planificar el territorio es el que se observa en el proceso de reconstrucción post 27-F, donde se han establecido cooperaciones entre ONG, entidades de educación privada y empresas mineras, quienes en asociatividad con los Gobiernos Locales de las localidades afectadas por la catástrofe han buscado dar una solución desde el enfoque del diseño urbano sustentable (Plan Chile Unido Reconstruye Mejor, 2010).

Producto de las nuevas cooperaciones entre diferentes actores y el Estado, se desarrollan 133 planes de reconstrucción ${ }^{2}$ a nivel nacional, que de acuerdo a su alcance y características territoriales se dividen en: 2 Planes de Reconstrucción Estratégica, 108 Planes de Regeneración Urbana y 23 Planes de Reconstrucción Estratégico Sustentable (Imilan y González, 2013).

La investigación de campo que da forma a este artículo se concentra en la última de las tipologías mencionadas, Planes de Reconstrucción Estratégico Sustentable (PRES), abordando específicamente el caso que involucre a las localidades de Duao, lloca y La Pesca, las cuales son tres pequeñas caletas pesqueras ubicadas en el extremo nor - oeste de la Región del Maule.

Metodológicamente se desarrolla desde lo que Jacques Derrida ${ }^{3}$ llamó deconstructivismo, es decir, se analiza el fenómeno en cuestión desde cada una de las partes que componen el problema, estudiando detalladamente su composición y alcances, para luego, cada una de las partes ser puestas en relación al total de antecedentes y analizarlos esta vez desde una perspectiva global. Es por ello que los antecedentes se presentan bajo una lógica secuencial de los hechos, los cuales son sustentados teóricamente a partir de la revisión bibliográfica de documentación oficial del Gobierno chileno e información oficial del Gobierno local.

El corte temporal de la investigación abarca desde Junio del año 2010 hasta Junio del año 2014. Sin embargo, es necesario señalar que la mayor cantidad de hechos vínculados a este proceso fueron desarrollados entre 2010 y 2012.

\subsection{Cuantificación de la catástrofe y reacción Estatal}

El sismo y posterior tsunami del 27-F impactó simultáneamente a seis regiones de Chile central, estas son: Valparaíso, L.G.B. O’Higgins, Maule, Biobío, Metropolitana y parte de la Araucanía. Además, en este espacio geográfico se localizan Valparaíso, Santiago y Concepción, las tres áreas metropolitanas más importantes del país. Dichas metrópolis concentran aproximadamente el 51\% de la población chilena con 8.380 .394 habitantes de acuerdo a resultados del Censo 2012 y un 16,6\% de las personas vive bajo la línea de la pobreza de acuerdo a lo reportado por la Encuesta CASEN del año 2011.

\footnotetext{
${ }^{1}$ De acuerdo a definición del Ministerio de Vivienda y Urbanismo, Reconstrucción, refiere a la acción de volver a levantar y construir algo material que ha sido destruido y también el tejido social, urbano y económico que ha sido devastado por acción de un desastre.

${ }^{2}$ El documento Plan Chile Unido Reconstruye Mejor, establece los líneamientos que contribuirán a la Reconstrucción Territorial, Urbana y Patrimonial de los 133 planes mencionados.

${ }^{3}$ Filósofo francés de origen argelino, el cual desarrolló el concepto de Deconstrucctivismo.

Modelo de gestión territorial utilizado en el proceso de reconstrucción post terremoto y tsunami del 27-F en Chile. Luis Eduardo González González. DOI 10.14198/i2.2015.04 
Innovación e Investigación en Arquitectura y Territorio. Departamento de Expresión Gráfica y Cartografía. Arquitectura. Escuela Politécnica Superior. Universidad de Alicante. №3 julio 2015

En las comunas donde se registraron daños existe una población de 7.415.944 habitantes potencialmente afectados, directa e indirectamente, de los cuales 370.051 resultaron damnificados (Plan Chile Unido Reconstruye Mejor, 2010). Esta cifra para efectos estadísticos se descompone de la siguiente manera: 81.444 viviendas destruidas, 108.914 viviendas con daño mayor y 179.693 viviendas con daño menor. Del total de damnificados sólo el 59,45\% resultaron ser familias habilitadas para recibir un subsidio habitacional por parte del Estado chileno.

En términos de infraestructura, 6 comunas presentaron puertos con daños aislados o severos; el principal aeropuerto internacional del país tuvo daños importantes; se registraron 44 comunas con colegios dañados; 39 comunas con hospitales afectados; 13 comunas con estadios dañados y 51 con daños de distinta magnitud en locales comerciales de importantes cadenas de supermercados, farmacias y tiendas de retail, entre otros (Plan Chile Unido Reconstruye Mejor, 2010). Estas cifras dan cuenta del alcance y magnitud del fenómeno, donde en la práctica no hubo lugar en Chile central que no fuera afectado por el sismo y, en las áreas costeras, por el posterior tsunami.

Por lo descrito previamente, el 27-F ha sido materia de permanente análisis tanto desde las esferas técnicas como desde las esferas políticas del país. En este escenario, el ex - Presidente de la República de Chile, Sebastián Piñera, en su discurso de 21 de Mayo del año 2011 señaló:

"Es necesario e importante reconocer que ese 27 de febrero la ONEMI - Organismo Nacional de Emergencias del Ministerio del Interior- no estaba preparada para asumir su desafío y cumplir la misión para la cual fue creada. Desde luego no está en nuestras manos impedir que la naturaleza vuelva a golpearnos". (Piñera, 2011)

Por otra parte, el 27-F desde la dimensión territorial tiene dos características fundamentales:

Primero, si bien fue percibido en una amplia zona del país, los mayores efectos del terremoto se evidenciaron en pequeños poblados rurales en el extremo sur de la Región del L.G.B. O'Higgins y parte del Maule, mientras que los efectos físicos y de mayor impacto producto del tsunami se localizaron en el borde costero de las Regiones del Maule y Biobío, destruyendo total y parcialmente pequeñas caletas de pesca artesanal que tenían su principal actividad económica vinculada al mar. Como consecuencia, la escala de los asentamientos urbanos que mayor daño presentaron por efectos del desastre son aquellos de tamaño menor, a los cuales el Instituto Nacional de Estadísticas (INE) los define como pueblos, villorrios y caseríos.

Segundo, la dispersión territorial de las localidades afectadas obligó al Estado a pensar soluciones particulares y de acuerdo a la realidad individual, resultando imposible generar una tipología de solución única para todos los damnificados y esto más tarde se transformó en una estrategia de reconstrucción.

\subsection{Planes maestros de reconstrucción urbano - habitacional}

Durante el año 2010, el Estado tomó una serie de medidas en materia de reconstrucción que serían más tarde las encargadas de orientar dicho proceso en el país. El paquete de medidas Estatales se empieza a gestar en marzo de aquel año y fueron plasmadas en el documento denominado Plan Chile Unido Reconstruye Mejor promovido por el Ministerio de Vivienda y Urbanismo (MINVU). Este plan buscaba sentar las bases para la intervención Estatal durante el proceso de reconstrucción, por lo que a poco andar estableció sus líneas de acción, respondiendo a las demandas sociales que apelaban a una reconstrucción justa y apropiada de acuerdo al contexto. De esta manera, nacieron los siguientes programas Estatales:

- Programa de Reconstrucción de Vivienda.

- Programa de Asistencia para Aldeas de Emergencia y Condominios Sociales.

- Programa Territorial, Urbano, y Patrimonial de Reconstrucción.

En adelante la investigación se concentrará en el último de los programas mencionados.

La implementación del plan de reconstrucción ha reconocido el papel fundamental que desempeña la colaboración pública y privada en todos los niveles de la organización del país, generando sinergias para la ciudad, lo cual es representado en la Fig. 1 en la cual se pone especial énfasis en el Programa objeto de este artículo. 


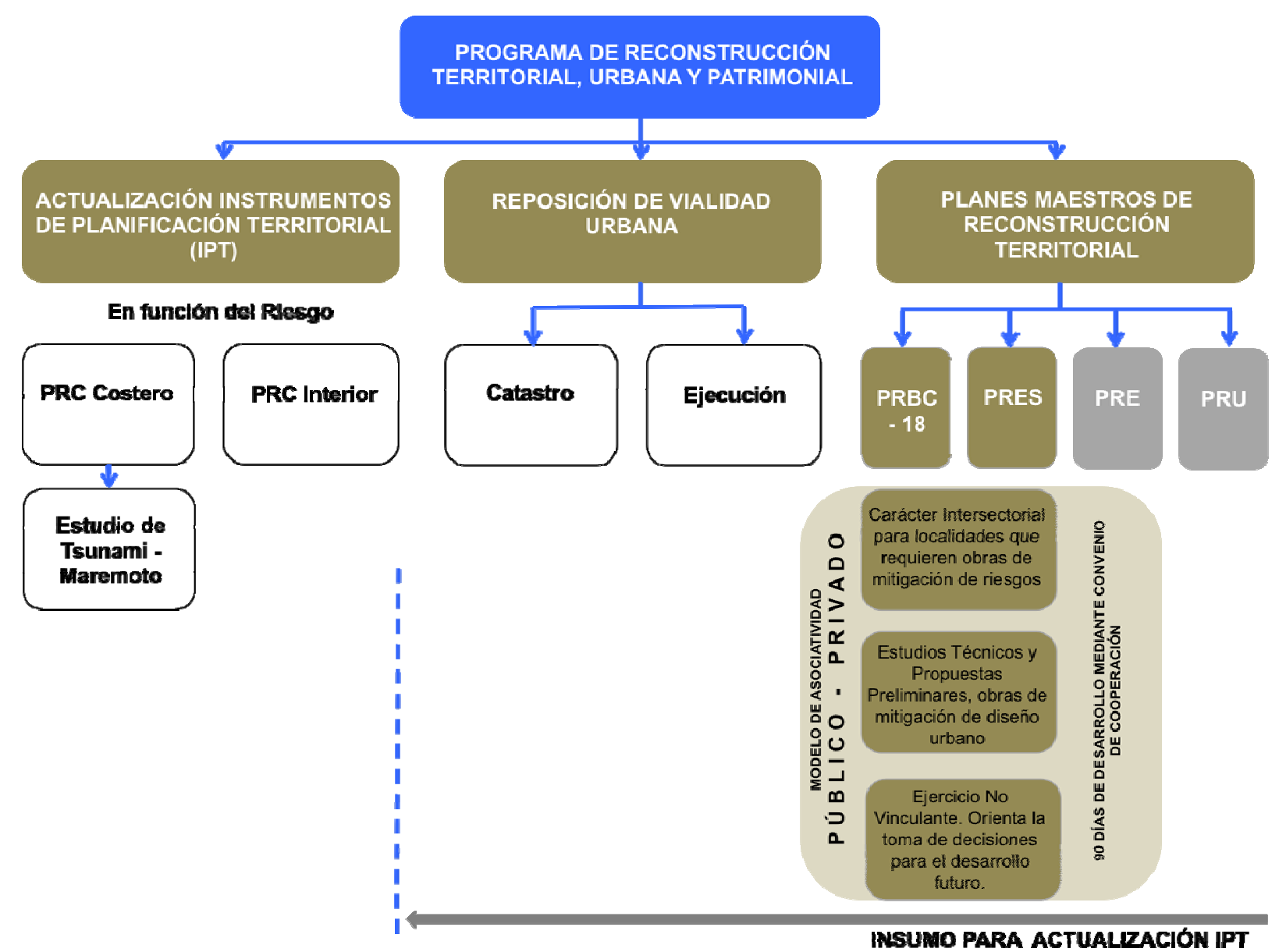

Fig. 1. Líneas de acción del Plan Estatal de Reconstrucción.

Fuente: Elaboración propia en base al Plan Chile Unido Reconstruye Mejor.

Desde el Estado se explicó de la siguiente manera el origen de sinergias y asociatividades entre actores públicos y privados durante el período de emergencia.

"En los primeros días después del desastre surgieron una amplia variedad de iniciativas de las organizaciones comunitarias, fundaciones, empresas privadas, organizaciones no gubernamentales, universidades $y$ organizaciones internacionales cuyo aporte no tiene precedentes en nuestro país". (Plan Chile Unido Reconstruye Mejor, 2010)

En este escenario, se constituye el Comité Interministerial de Infraestructura y Reconstrucción, donde convergen los planes de Reconstrucción de los Ministerios de Obras Públicas, Interior, Educación, Salud, Economía, además de Vivienda y Urbanismo. Este es un hecho sin precedente, ya que el comité buscará la integración de proyectos complejos y asegurar su ejecución en un período de 8 años.

\subsection{Planes maestros de reconstrucción urbano - territorial}

El mes de abril del año 2010 marca el inicio formal de los planes maestros de reconstrucción territorial y también de la actualización y/o modificación de los Instrumentos de Planificación Territorial (IPT), de acuerdo a lo establecido en la Ley de Catástrofes para las zonas afectadas por el 27-F.

Los PRES, PRE y PRU se gestaron gracias a la presión de actores locales, que buscaban agilizar la zonificación del territorio, la definición de usos de suelo y coordinar las diferentes muestras solidarias por parte de instituciones públicas y privadas.

En este escenario se desarrollaron tres tipologías de planes estratégicos, diferenciados desde la realidad geográfica que deben enfrentar, ver Fig. 2. 
Tipos de Instrumentos

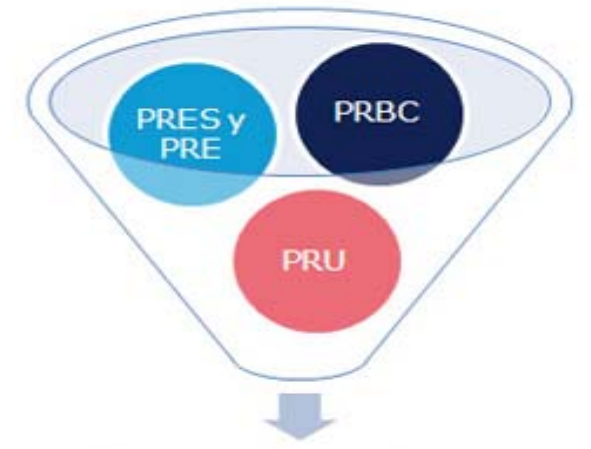

Planes Maestros

\section{Aplicación Territorial}

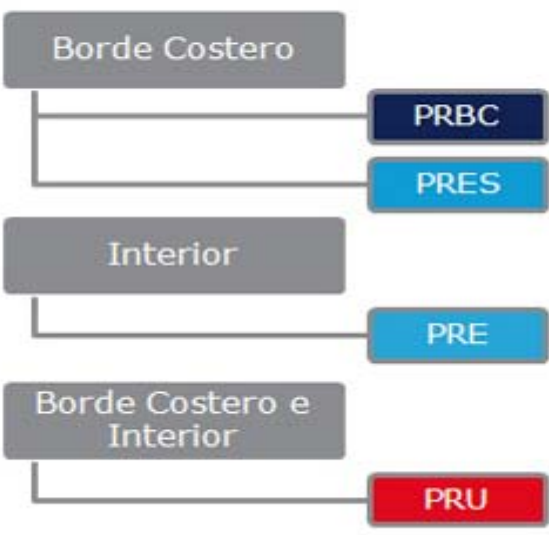

Fig. 2. Tipos de planes maestros gestados en la reconstrucción post 27-F.

Fuente: <http://www.minvu.cl/opensite_20100902171801.aspx> (Consultada 13 Febrero 2014)

La primera tipología corresponde a los Planes de Regeneración Urbana (PRU), los cuales han sido encargados de dar una respuesta urbana a pequeñas y medianas localidades de las regiones de Valparaíso, Metropolitana, L.G.B. O’Higgins, Maule, Biobío y Araucanía, lugares donde la imagen urbana se vio afectada a causa del 27-F. Como consecuencia de dicho proceso, el objetivo principal de los PRU ha sido atenuar la presión por reconstruir rápidamente y orientar la reconstrucción armónica de localidades, barrios y ciudades cuyo origen e identidad se han visto amenazados por las dinámicas propias del proceso que se encuentran viviendo. Además buscan proteger el valor del conjunto armónico de la arquitectura local. ${ }^{4}$

Metodológicamente los PRU son articulados desde los siguientes cuatro objetivos básicos, donde cada uno de ellos corresponde a una fase de su desarrollo.

- Fase 1: Propuesta urbana.

- Fase 2: Desarrollo del PRU.

- Fase 3: Desarrollo de proyectos en detalle, gestión y ejecución.

- Fase 4: Incorporación del PRU al IPT y a estudios de integración territorial.

Esta metodología desde sus inicios hasta el presente ha sido coordinada desde la División de Desarrollo Urbano de las Secretarías Regionales del Ministerio de Vivienda y Urbanismo (SEREMI MINVU) donde se elaboraron 20 planes piloto.

Los planes previamente enunciados, junto a los planes maestros para localidades del borde costero, tienen en común la coordinación interministerial, estudios técnicos - propuestas y estudios de apoyo a la planificación urbana, debido a que son ejercicios proyectuales realizados mediante convenios de cooperación y asociatividad. Este ha sido un proceso que busca producir una cartera de inversión en el territorio, diferenciando entre: PRBC18 y PRES. Básicamente el primero abarca a las comunas costeras de la Región del Biobío en un plan macro, mientras que el segundo tiene como campo de acción localidades de la Región de Valparaíso y el Maule de forma separada, no obstante su objetivo es el mismo, orientar la reconstrucción y velar por el valor armónico y unitario de la intervención.

\footnotetext{
${ }^{4}$ De acuerdo al Plan Chile Unido Reconstruye Mejor, el cual tiene su primera versión el año 2010. 
Innovación e Investigación en Arquitectura y Territorio. Departamento de Expresión Gráfica y Cartografía.

Arquitectura. Escuela Politécnica Superior. Universidad de Alicante. №3 julio 2015

ISSN: 2341-0515

\section{Análisis del plan de reconstrucción estratégico sustentable (PRES) de Duao, lloca y La Pesca}

- Objetivo general

Realizar una descripción analítica sobre el funcionamiento y articulaciones generadas por el modelo de gestión territorial utilizado en Chile luego del 27-F, reconociendo a este modelo como una herramienta de planificación territorial que es gestada desde las políticas públicas vigentes en Chile.

- Objetivos específicos

Primero, identificar y caracterizar el mapa de actores presentes en el modelo de gestión PRES de Duao, lloca y La Pesca, durante su etapa de diseño e implementación.

Segundo, identificar los alcances y limitaciones del modelo de gestión en su implementación en el territorio de Duao, lloca y La Pesca.

- Preguntas de investigación

¿Cuáles son los efectos del proyecto PRES sobre el Hábitat Residencial de las localidades de Duao, lloca y La Pesca?

Esta pregunta se formula debido a que el PRES implementa un modelo de gestión novedoso en su forma de intervenir y planificar el territorio en Chile. No obstante, los antecedentes iniciales del caso de estudio indican que el impacto del plan Estatal de reconstrucción no ha logrado incidir positivamente en las dinámicas socio - urbanas del lugar. Siendo un aspecto central que esta investigación busca demostrar.

Por otra parte, ¿Cuál es el contexto en que se construye el mapa de actores presentes en el proyecto PRES con carácter de laboratorio urbano?

\subsection{Deconstrucción modelo de gestión PRES de Duao, lloca y La Pesca}

En términos de estructura básica el tsunami del 27- $F$ fue exponencialmente más destructivo que el terremoto mismo. La evidencia física revela que el tsunami barrió con elementos urbanos indispensables para el funcionamiento de las ciudades, tales como: vialidades, puertos y muelles, servicios públicos, equipamiento de emergencia, de comercio e intercambio de bienes y áreas destinadas a la residencia. ${ }^{5}$

Respecto a la diferencia exponencial de daños en la trama urbana provocada por el tsunami versus los efectos del terremoto, es posible sostener que "la geografía de nuestro país y la realidad espacial de la ocupación de nuestro territorio entabla una serie de peligros latentes que, combinados con focos de vulnerabilidad, incrementan los niveles de riesgo" (Arenas, Lagos e Hidalgo, 2010).

Lo anterior sucede debido a que el patrón de trazados urbanos en el borde costero de Chile se estructura desde un eje longitudinal constituido por una vía vehicular, paralelo a la línea de las mareas y en torno a la cual se emplazan: zonas de pesca, comercio, servicios públicos y áreas residenciales, quedando todo ello espacialmente encajonado por la Cordillera de la Costa, en una franja no mayor a 500 metros de ancho y siendo aquellas zonas vulnerables a las olas producidas durante el $27-\mathrm{F}$.

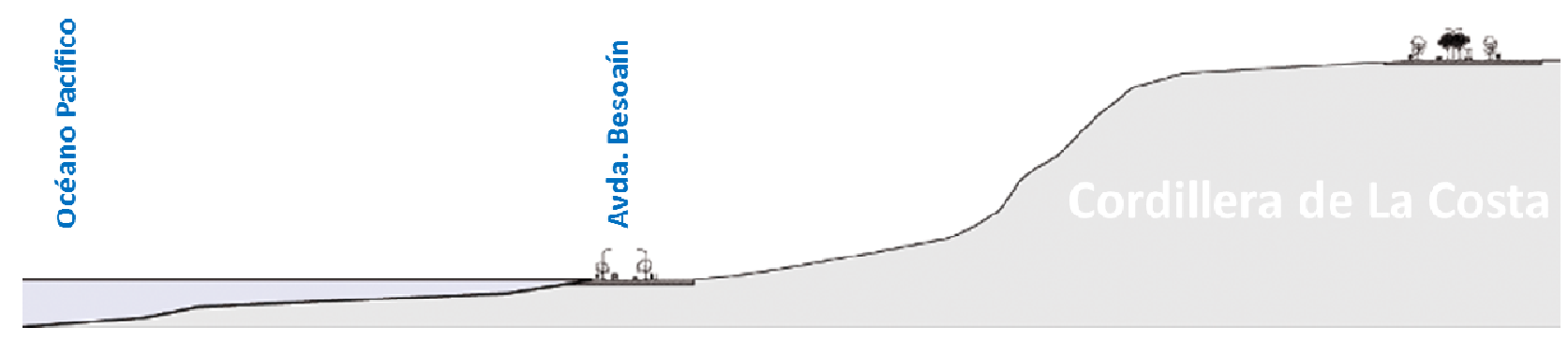

Fig. 3. Corte Topográfico tipo de lloca. Fuente: Presentación HATCH del PRES Duao, lloca y La Pesca, imagen Intervenida.

\footnotetext{
${ }^{5}$ El informe de daños inserto en el Plan Chile Unido Reconstruye Mejor también refleja en términos estadísticos ésta información. La cual para efectos de estas localidades ha sido contrastado con lo existente en terreno, primero durante el año 2010 y luego durante el primer semestre del año 2012.
}

Modelo de gestión territorial utilizado en el proceso de reconstrucción post terremoto y tsunami del 27-F en 
Innovación e Investigación en Arquitectura y Territorio. Departamento de Expresión Gráfica y Cartografía. Arquitectura. Escuela Politécnica Superior. Universidad de Alicante. №3 julio 2015

Frente a la constante exposición al riesgo, en el año 2010 el Estado buscó dar una solución territorial y arquitectónica a los crecientes problemas urbanos de las localidades afectadas. La propuesta consistió en la implementación de los planes maestros que se caracterizaban por su innovación metodológica y por un diseño que sólo tomaría 90 días (Convenio de Cooperación, 2010).

En este contexto, una iniciativa de reconstrucción de borde costero gestada durante aquel año y relevante de analizar, es el caso del PRES de Duao, lloca y La Pesca, Comuna de Licantén, Región del Maule.

En dichas localidades y luego del desastre, rápidamente se pusieron en acción una serie de medidas desde el Gobierno Central y Local que apuntaban a revertir el panorama desolador que causó el 27-F. Dentro de los principales daños físicos sucedidos en estas localidades es posible mencionar la destrucción parcial y/o total de: caminos, puentes, oficinas públicas, Retén de Carabineros, Cuerpo de Bomberos, servicios de salud rural, caleta de pescadores, tres Escuelas Básicas, tres plazas públicas, el terminal de buses, edificios destinados al culto religioso y propiedades particulares relacionadas al comercio y residencia. Tal fue el impacto mediático de la destrucción territorial que en muy poco tiempo la Comuna de Licantén recibió ayuda material y económica de distintas instituciones públicas y privadas tanto del país como del extranjero, las cuales estaban interesadas en contribuir con el proceso de reconstrucción, atraídas principalmente, por las imágenes y videos que empezaron a circular de su destruido borde costero en los medios de comunicación.

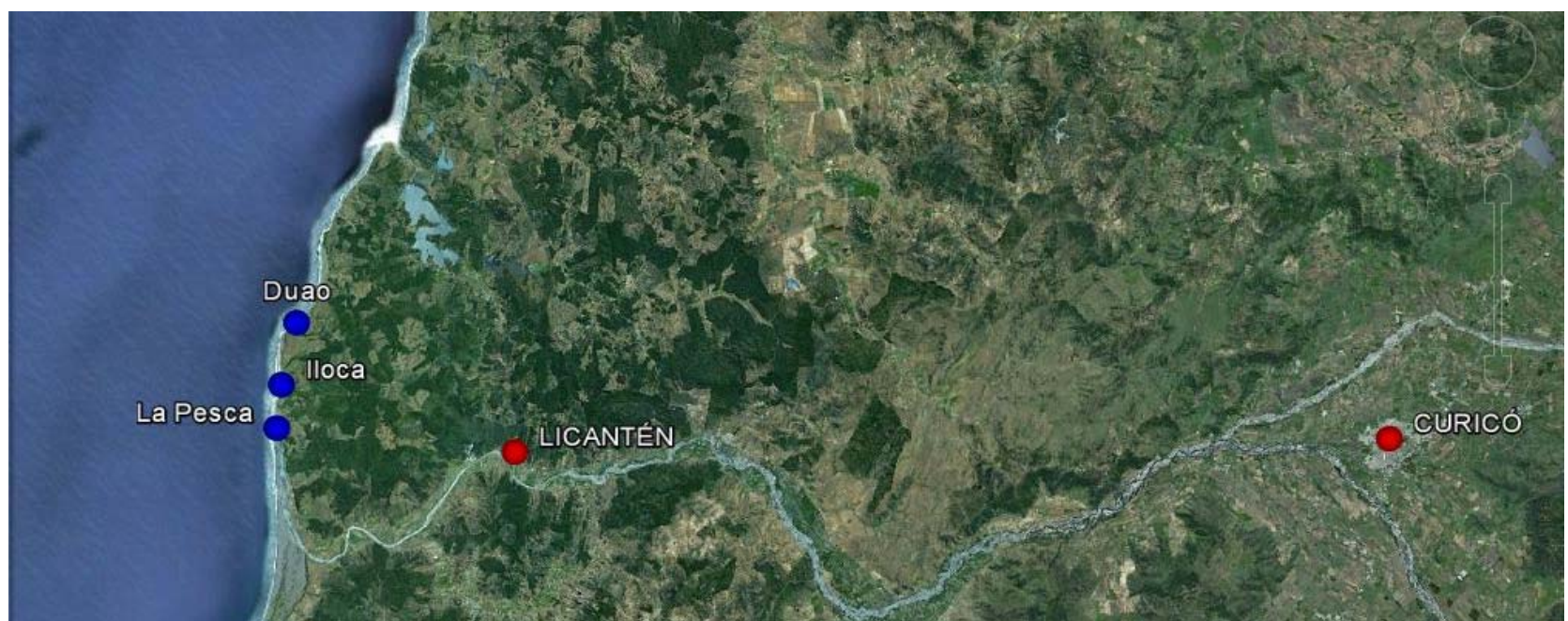

Fig. 4. Fotografía área donde se muestra la ubicación de Duao, lloca y La Pesca, emplazadas al oeste de la Capital Provincial Curicó y distantes $24 \mathrm{Km}$ desde la Capital Comunal, Licantén. Ubicadas específicamente en la desembocadura del Rio Mataquito al Océano Pacífico. Fuente: Google Earth intervenida.

La presente es una investigación que busca dilucidar cómo localidades hasta entonces poco o nada conocidas en el mapa de asentamientos costeros de Chile son objeto de intervención por parte del Estado con las propuestas territoriales más innovadoras que se hayan gestado en los últimos años en el país.

Para construir el escenario en el cual se desarrollan las acciones del PRES se revisarán las características del modelo de gestión territorial que le da forma, es decir, el Convenio de Cooperación.

\subsection{Convenio de cooperación PRES: Modelo de gestión y resultados en el territorio}

Durante el proceso de reconstrucción post 27-F se creó el cargo de Coordinador Nacional de la Reconstrucción Territorial Urbana, cargo del cual fue responsable el arquitecto Sr. Pablo Allard, quien en entrevista al sitio web Plataforma Urbana durante el año 2010 declaró lo siguiente:

"Para la planificación estamos haciendo en esta primera fase levantar y hacer un catastro de todas colaboraciones que se están dando de forma espontánea de organizaciones civiles, grupos de amigos de un poblado o una ciudad. Empresas privadas que quieran hacer aportes y que ya han hecho, haciendo convenios con municipios $y$ nosotros como gobierno lo que hemos hecho es darle un marco y tratar de generar convenios que garanticen que ejercicios como planes maestros, como posibles proyectos detonantes, trabajos de colaboración en la construcción de escuelas no queden solamente como medidas de emergencia, no queden como expectativas de un 
Innovación e Investigación en Arquitectura y Territorio. Departamento de Expresión Gráfica y Cartografía. Arquitectura. Escuela Politécnica Superior. Universidad de Alicante. №3 julio 2015

futuro posible, sino que generar insumos si es que los validamos técnicamente y con la comunidad para actualizar los planos reguladores y las acciones que claramente tiene que hacer el Estado que es velar porque ese desarrollo se dé de forma armónica". (Allard, 2010)

Posterior a esto, en el mes de mayo se materializaron Convenios de Cooperación entre entidades privadas con organismos públicos. Tales convenios son resultado de iniciativas privadas que buscaban contribuir al proceso de reconstrucción.

La anterior es una etapa que no estuvo exenta de cuestionamientos por parte de la opinión pública y la ciudadanía. Al respecto Allard indica.

"En esta primera fase, hemos hecho un catastro de todas las colaboraciones que se han dado de forma espontánea de organizaciones civiles, grupos de amigos de un poblado o una ciudad; Empresas privadas que quieran hacer aportes y que ya han hecho, por esto estamos haciendo convenios con municipios y nosotros como Gobierno lo que hemos hecho es darle un marco que garanticen ejercicios como planes maestros o posibles proyectos detonantes, que no queden sólo como expectativas de un futuro posible; sino que sean validados técnicamente y con la comunidad". (Allard, 2010)

De esta manera, es posible sostener que la gestación del PRES ocurre en las altas esferas empresariales, trasladándose luego el modelo ${ }^{6}$ al territorio y a las autoridades políticas del país, lo cual en opinión del autor elude un integrante fundamental para la correcta concreción de la iniciativa, la población objetivo del proyecto.

El Ministerio de Vivienda y Urbanismo en conjunto con entidades públicas y organizaciones educativas privadas dieron forma a los Convenios de Cooperación con el propósito de superar el estado de emergencia y buscar los siguientes objetivos:

- Incrementar las fortalezas y/o ventajas competitivas de los centros urbanos, permitiendo redefinir su desarrollo futuro.

- Orientación a mejorar la planificación para un desarrollo urbano sustentable y al mismo tiempo abordar racionalmente los riesgos de la naturaleza.

- Ser un modelo replicable.

En consecuencia, el PRES parece ser visto desde el Estado como la oportunidad de generar cambios importantes a nivel local, tal como lo señalaba años antes el economista y mentor de la Escuela de Chicago, Milton Friedman.

"solo una crisis - real o percibida - da lugar a un cambio verdadero. Cuando esa crisis tiene lugar, las acciones que se llevan a cabo dependen de las ideas que flotan en el ambiente. Creo que esa ha de ser nuestra función básica: desarrollar alternativas a las políticas existentes, para mantenerlas vivas y activas hasta que lo políticamente imposible se vuelve políticamente inevitable".?

Luego de firmado el convenio de cooperación, la entonces Ministra del Ministerio de Vivienda y Urbanismo, señaló que "sin este tipo de convenios sería más difícil el arreglo debido a la magnitud del desastre. Esta es una alianza importante para recuperar lugares como Licantén" (Matte, 2010). Con esta declaración se dejó claro que el aporte e involucramiento del sector privado era el modelo de actuación territorial que permitiría la reconstrucción del país.

En este escenario, el convenio establecía una serie de gestiones que debían ser realizadas para asegurar el éxito del proyecto y en el largo plazo del plan. Sus objetivos eran los siguientes:

- "Estructurar un modelo de gestión replicable, que se sustente en la colaboración y acción conjunta del gobierno central, el gobierno regional, el municipio y empresas que se interesen en participar en esta tarea.

- Gestionar el desarrollo de un Plan Maestro por parte de un consorcio de instituciones y consultores calificados, que permitirá ordenar y orientar las inversiones públicas y los aportes privados.

- Establecer las bases para llevar adelante un Plan de Inversiones y aportes necesarios para la reconstrucción de las localidades de Iloca, Duao y La Pesca, Comuna de Licantén". (Convenio de Cooperación PRES Duao, lloca y La Pesca, 2010)

\footnotetext{
${ }^{6}$ Se entenderá Modelo de Gestión desde la descomposición de los términos; Modelo, haciendo referencia a un arquetipo que, por sus características es susceptible de ser reproducido, por tanto, es un esquema teórico que representa una realidad compleja a la que busca dar solución. Por otra parte Gestión hace referencia a la acción de gestionar y administrar. En consecuencia un Modelo de Gestión es un esquema para la administración de una institución, o como en nuestro caso particular; para llevar adelante un plan y lograr los objetivos para el cual fue creado, a través de políticas y acciones concretas; tales como gobernar, dirigir y ordenar.
}

${ }^{7}$ FRIEDMAN, Milton, a través de KLEIN, Naomi. La doctrina del shock. El auge del capitalismo del desastre. Barcelona, Paidos, 2010. $702 \mathrm{p}$.

Modelo de gestión territorial utilizado en el proceso de reconstrucción post terremoto y tsunami del 27-F en Chile. Luis Eduardo González González. DOI 10.14198/i2.2015.04 
Los tres lineamientos del convenio PRES reafirman el carácter ejecutivo que se había atribuido al proceso de reconstrucción, ya que buscan coordinar actores bajo una lógica de consultorías, quizás sin considerar la variable social, interviniendo el territorio local para la consecución de las metas cuantitativas establecidas desde el Estado. De esta manera el modelo PRES puede ser representado a partir de la Fig. 5.

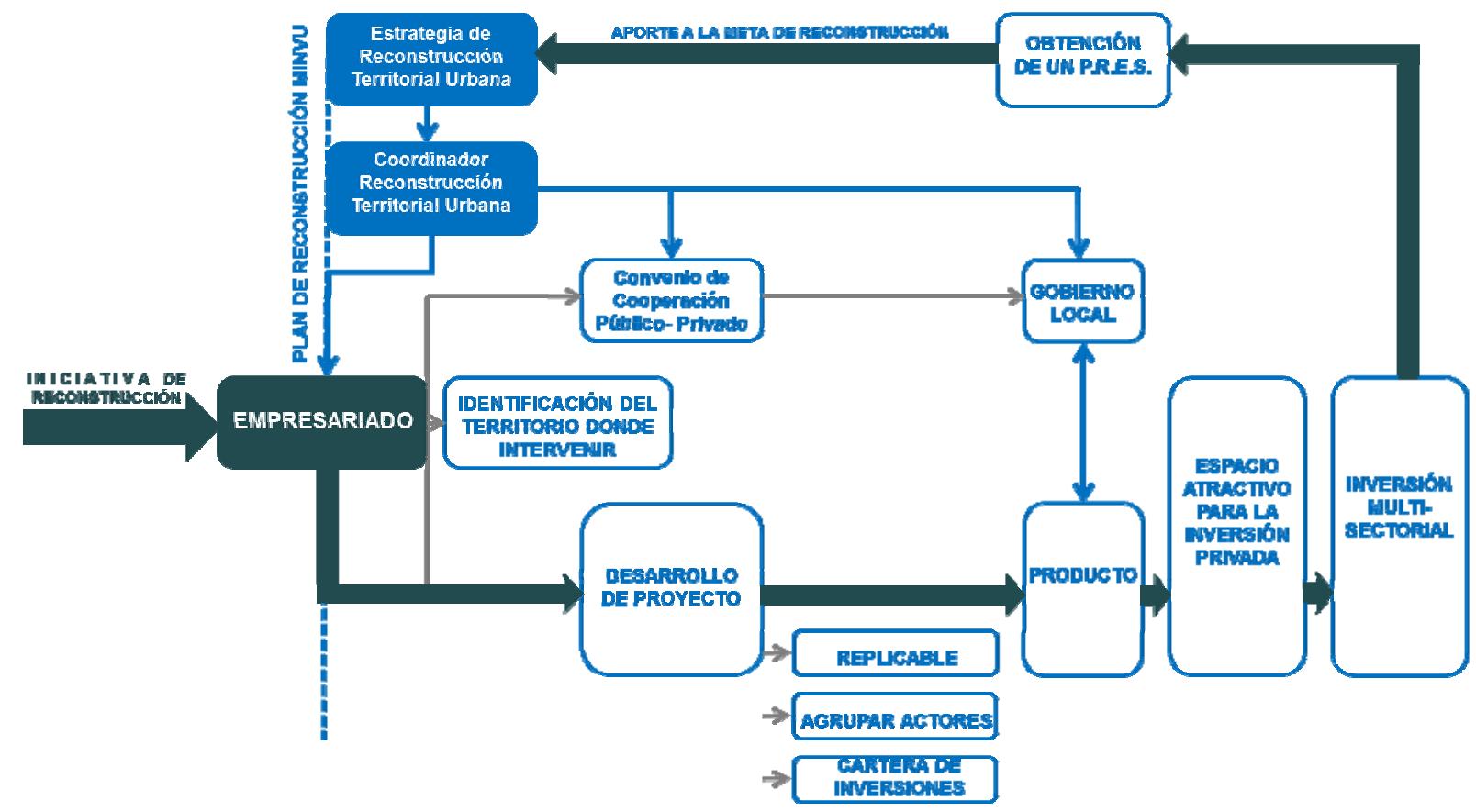

Fig. 5. Modelo de Gestión utilizado en el P.R.E.S de Duao, Iloca y La Pesca.

Fuente: Elaboración propia, en función del Convenio de Cooperación del PRES de Duao, lloca y La Pesca.

A partir del modelo de gestión es posible entender el tipo de estructura que plantea el convenio, donde es el empresariado el gestor de la iniciativa de reconstrucción. Por lo tanto, nacen desde necesidades para unos y oportunidades para otros de materializar una propuesta urbana, respondiendo a distintos tipos de intereses. A continuación se enuncian los productos específicos que debía lograr el PRES.

- "Diseño de una imagen objetivo, de acuerdo a una visión estratégica de desarrollo.

- Diseño urbano, definiendo zonas, usos de suelo, conectividad, zonas de riesgos y medidas de mitigación, entre otras.

- Vivienda, identificación de la demanda, propuestas tipológicas y estudio de la oferta de inversión pública.

- Plan de Gestión de Riesgos Naturales, esta debía definirse en función de las zonas de riesgos identificadas.

- Plan de Gestión del Patrimonio, delimitando zonas de conservación y evaluación presupuestaria.

- Propuesta Inmobiliaria, por tanto generar un estudio de mercado y potenciales modelos de negocio.

- Factibilidad Económica y Financiera, involucrando aquí una evaluación de factibilidad económica, social y privada del plan.

- Plan de Inversiones Priorizado, definiendo proyectos de inversión públicos y privados.

- Plan de Gestión de activos, identificando suelos tanto públicos y privados susceptibles de expropiación, permutas $u$ otra acción legal.

- Proposición de una obra emblemática del PRES.

- Guías de Diseño, con propósito de resguardar una imagen urbana coherente.

- Propuestas de modificación al IPT.

- Estrategia de sustentabilidad ambiental.

Modelo de gestión territorial utilizado en el proceso de reconstrucción post terremoto y tsunami del 27-F en

Chile. Luis Eduardo González González. DOI 10.14198/i2.2015.04 
Innovación e Investigación en Arquitectura y Territorio. Departamento de Expresión Gráfica y Cartografía. Arquitectura. Escuela Politécnica Superior. Universidad de Alicante. №3 julio 2015

- Plan de Comunicación estratégica, tendientes a posicionar favorablemente el PRES en los medios de comunicación.

- Participación Ciudadana, tendientes a identificar las necesidades y demandas para conocer el capital social.

- Programación PRES a partir de un escenario base y tendencial". (Convenio de Cooperación PRES Duao, lloca y La Pesca, 2010)

En este caso de estudio se aplicó un modelo genérico de implementación del PRES, donde una empresa de carácter minero se interesa en regalar un plan para las localidades de Duao, lloca y La Pesca. Frente a esta oportunidad de cooperación, el Estado, a través de su línea de Reconstrucción Territorial y Patrimonial fija límites legales para la intervención a través de un Convenio de Cooperación entre ambos actores más el Gobierno Local. De esta manera se desarrolló un proyecto urbano que estableció las bases para la inversión pública y privada, el cual tendrá un plazo de 8 años para consolidarse (2010-2018), de acuerdo a los 16 puntos previamente enunciados.

Antecedentes presentados previamente hacen cuestionar la integralidad del PRES, el cual en términos proyectuales es una iniciativa propositiva e interesante desde la arquitectura como ámbito disciplinar. No obstante, se plantea que el Hábitat Residencial y su estructura multi-escalar se construye desde diferentes aristas para lograr la integralidad y por tanto su éxito, siendo el PRES carente de esta cualidad, al menos en su modelo de gestión. El autor plantea esto debido a que la propuesta nace desde lo abstracto y atemporal, no incorporando las dinámicas sociales de relaciones entre comunidades, actividades productivas, desplazamientos desde y hacia los lugares de trabajo, relaciones con su entorno natural y construido, etc. Tales características son trascendentales, dado que se sostiene firmemente que un plan de inversión de la magnitud que genera el PRES es infértil si no es consensuado con la comunidad, para asegurar la validación total frente a los actores involucrados.

\subsection{Mapa de actores presentes en el PRES de Duao, lloca y La Pesca}

Durante el año 2010, se llevó a cabo la parte operativa del Convenio de Cooperación PRES firmado por los cuatro actores claves de este proceso y que a continuación se identifican.

En primer lugar $\mathrm{HATCH}$, mentores de esta iniciativa, es una empresa canadiense e internacionalmente reconocida por su trabajo prestando servicios de ingeniería, gerenciamiento de proyectos y de administración de la construcción, consultoría de procesos, de negocios y servicios operacionales a la industria minera, metalurgia, energía e infraestructura. Su característica fundamental radica en sus 80 años de experiencia y haber prestado servicios en más de 150 países, permitiéndole esto posicionarse como una empresa global capaz de abarcar todo el proceso de un proyecto consultivo. ${ }^{8}$

"este es un plan realista, participativo y profesional. Son tres características que lo hacen un muy buen plan. Hemos aprendido el proceso para hacer otros planes, el compromiso con la ciudadanía y con la empresa HATCH, más la Universidad Mayor, quienes nos han donado este plan para que lo podamos ejecutar y hacerlo muy bien [...] donde esperamos que HATCH nos siga acompañando en este proceso, porque coordinar una serie de obras con distintos Ministerios requiere de toda la experiencia que tiene HATCH en sus proyectos alrededor del mundo". (lacobelli, 2010)

De las palabras de lacobelli, entonces Subsecretario del Ministerio de Vivienda y Urbanismo, se desprende que la experiencia internacional de HATCH ha sido sinónimo de confiabilidad y seguridad para que desarrolle el plan de reconstrucción.

Sin embargo y si recordamos a Klein, deberíamos preguntarnos ¿qué obtiene HATCH a cambio de aportar recursos para un plan de reconstrucción? Quizás, una posible respuesta la encontremos en el concepto Responsabilidad Social Empresarial ${ }^{9}(\mathrm{RSE})$, concepto que simultáneamente repercute en el marketing urbano ${ }^{10}$ de la marca HATCH, logrando posicionarse en el mercado como una empresa que coopera con la Reconstrucción aportando un plan innovador. Por lo tanto, se plantea que el beneficio del privado en este caso no es nocivo y tampoco ilegal, sino que está dentro de las estrategias de comunicación de una marca frente a la ciudadanía,

\footnotetext{
${ }^{8}$ De acuerdo a antecedentes tomados desde <http://www.hatch.cl> (Consultada el 12 Febrero 2015).

${ }^{9}$ De acuerdo a Biblioteca del Congreso Nacional de Chile, puede definirse como un compromiso entre el sector empresarial y la sociedad civil para crear una instancia de cooperación que permita mejorar las condiciones de vida tanto de sus trabajadores como del resto de la población. La Fundación PROHumana amplía esta explicación diciendo que es; lo que la empresa hace como "contribución al desarrollo humano sostenible, a través del compromiso y confianza con sus empleados y familias, la sociedad en general y la comunidad local en pos de mejorar su capital social y calidad de vida".

${ }^{10}$ El marketing urbano constituye una nueva etapa en la evolución del marketing "clásico". Probablemente es uno de los últimos campos de aplicación de esta disciplina microeconómica. O bien una forma en que las ciudades intentan posicionarse en un mundo globalizado.

Modelo de gestión territorial utilizado en el proceso de reconstrucción post terremoto y tsunami del 27-F en 10 Chile. Luis Eduardo González González. DOI 10.14198/i2.2015.04
} 
Innovación e Investigación en Arquitectura y Territorio. Departamento de Expresión Gráfica y Cartografía. Arquitectura. Escuela Politécnica Superior. Universidad de Alicante. №3 julio 2015

logrando el plus de ser avalada por el Estado.

En segundo y tercer lugar, dentro del mapa de actores del PRES se encuentra el arquitecto Ricardo Stein, quien se asocia a la Facultad de Arquitectura de la Universidad Mayor (FAUM) y además con HATCH, para desarrollar de manera conjunta el proyecto.

Una vez firmado el Convenio de Cooperación, se empieza a elaborar la propuesta territorial de manera conjunta entre los actores mencionados anteriormente, equipo liderado por Antonio Polidura ${ }^{11}$ quien sostiene que "esta fue una intervención a futuro". (Polidura, 2012)

Presentados los actores que gestan el proyecto y luego lo territorializan, es claro que ambos privados se posicionan como socios estratégicos del Estado durante la reconstrucción. Este simple alcance hace reflexionar sobre la distancia que toman los actores públicos en este proceso, ya que la consecuencia es que ven disminuida su incidencia sobre el propio territorio, el cual es entregado a terceros para que generen propuestas de desarrollo para los próximos 8 años.

Finalmente, un cuarto actor presente en el Convenio y como parte del Estado en su escala regional se encuentra la Secretaría Regional del Ministerio de Vivienda y Urbanismo (SEREMI MINVU) de la Región del Maule, quien fue la encargada a través de su Departamento de Desarrollo Urbano (DDU) de supervisar el correcto avance del convenio en cuestión.

En la Fig. 6 se grafican los actores que participan del Convenio de Cooperación.

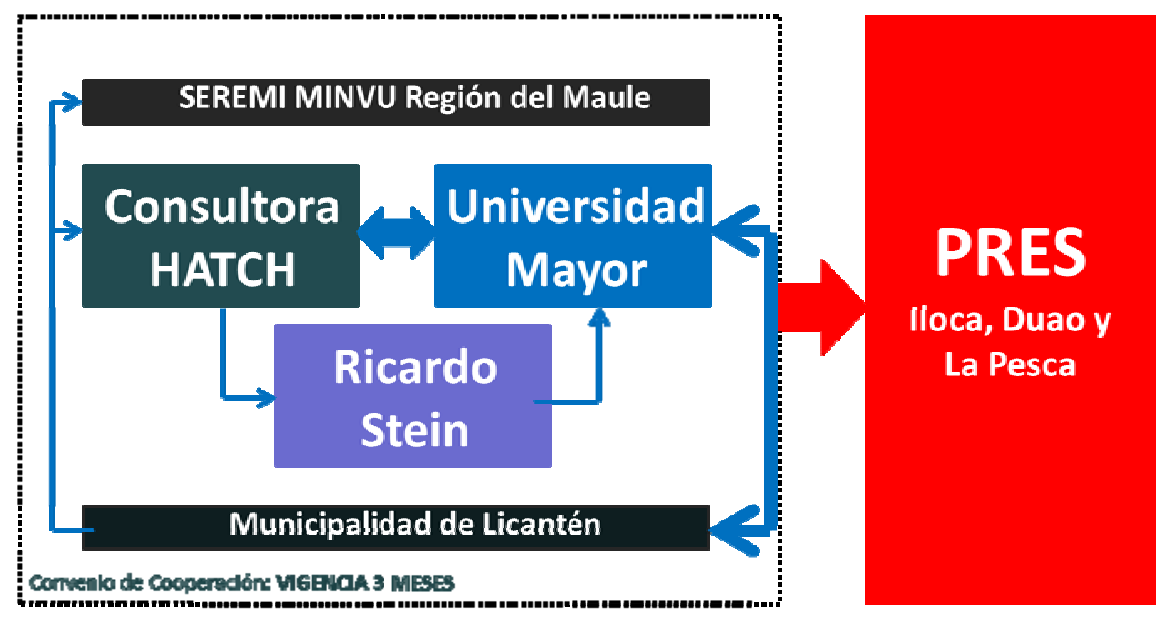

Fig. 6. Actores participantes en el Convenio de Cooperación PRES de Duao, lloca y La Pesca.

Fuente: Elaboración propia, en función del Convenio de Cooperación del PRES de Duao, lloca y La Pesca.

Pese a la conformación oficial del Mapa de Actores presentes en el territorio y de acuerdo a lo indicado en el Convenio de Cooperación, también han existido otros actores que dialogan de manera tangencial con este proyecto PRES, es decir, inciden en su desarrollo pero no de una manera vinculante. Es por ello que el mapa de actores que mejor refleja el desarrollo de la reconstrucción en Duao, lloca y La Pesca es el de la Fig. 7.

\footnotetext{
${ }^{11}$ Destacado arquitecto chileno que lideró el equipo encargado de la propuesta arquitectónica en el PRES de Duao, lloca y La Pesca. Primero desde la Universidad Mayor y luego desde la Universidad Finnis Terrae.

Modelo de gestión territorial utilizado en el proceso de reconstrucción post terremoto y tsunami del 27-F en 11 Chile. Luis Eduardo González González. DOI 10.14198/i2.2015.04
} 


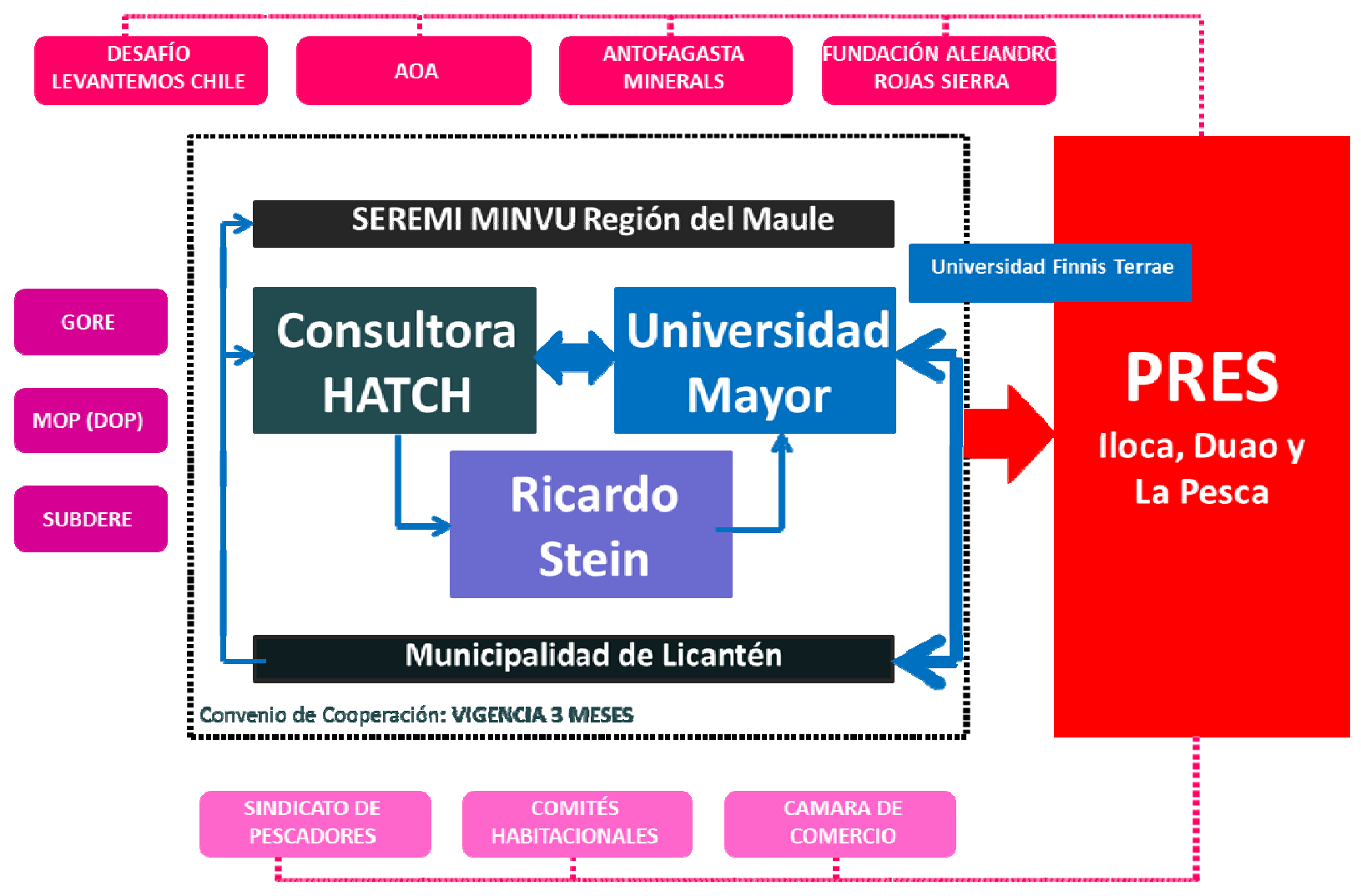

Fig.7. Actores que inciden en el P.R.E.S de Duao, lloca y La Pesca.

Fuente: Elaboración propia, en función del Convenio de Cooperación del P.R.E.S. de Duao, lloca y La Pesca.

Mediante la Fig. 7 se pone de manifiesto el ingreso de nuevos actores a cambio de otros que abandonaron el proyecto. Tal es el caso del Centro de Proyectos Externos de la Universidad Mayor, que cierra sus puertas a fines del año 2011 y durante el 2012 pasa a formar parte de la Universidad Finnis Terrae, por lo tanto, Antonio Polidura encargado técnico del proyecto cambia de casa de estudios y actualmente trabaja el PRES en conjunto con el conocido arquitecto chileno Felipe Assadi, decano de la Facultad de Arquitectura y Diseño de la Universidad Finnis Terrae, demostrando también que los protagonistas del proyecto mantienen la esperanza de que éste pueda ser desarrollado y ejecutado.

\subsection{Valoración de los efectos del PRES de Duao, lloca y La Pesca}

\subsubsection{Efectos sobre dimensión socio - económica}

A poco más de cuatro años de sucedido el 27-F el efecto no visible del proceso de reconstrucción y del proyecto PRES ha sido potenciar las disputas históricas entre las diferentes localidades.

Ello ha sido producto de acciones tales como, materialización de iniciativas de alta inversión económica concentradas en localidades previamente establecidas tanto desde el sector público como desde el privado y la no atención a zonas históricas y de una importancia sentida para comunidad. Esto por tratarse de sectores donde predomina la segunda vivienda y/o residencias ligadas al comercio de escala familiar (residenciales, cabañas y camping). Antecedentes que cruzados con los efectos visibles de daños, recogidos por el PRES en su etapa de estudio, han derivado en la especulación al interior de las comunidades, cuestionando permanentemente los lugares donde debiese concentrase la inversión pública y ayuda hacia las familias afectadas parcialmente y con 
Innovación e Investigación en Arquitectura y Territorio. Departamento de Expresión Gráfica y Cartografía. Arquitectura. Escuela Politécnica Superior. Universidad de Alicante. №3 julio 2015

pérdida total de sus bienes. Hechos ciertos que finalmente repercuten en un proceso de participación ciudadana con distintos grados de representatividad y validación comunitaria, quienes lo observan como beneficios para algunos sectores en desmedro de otros.

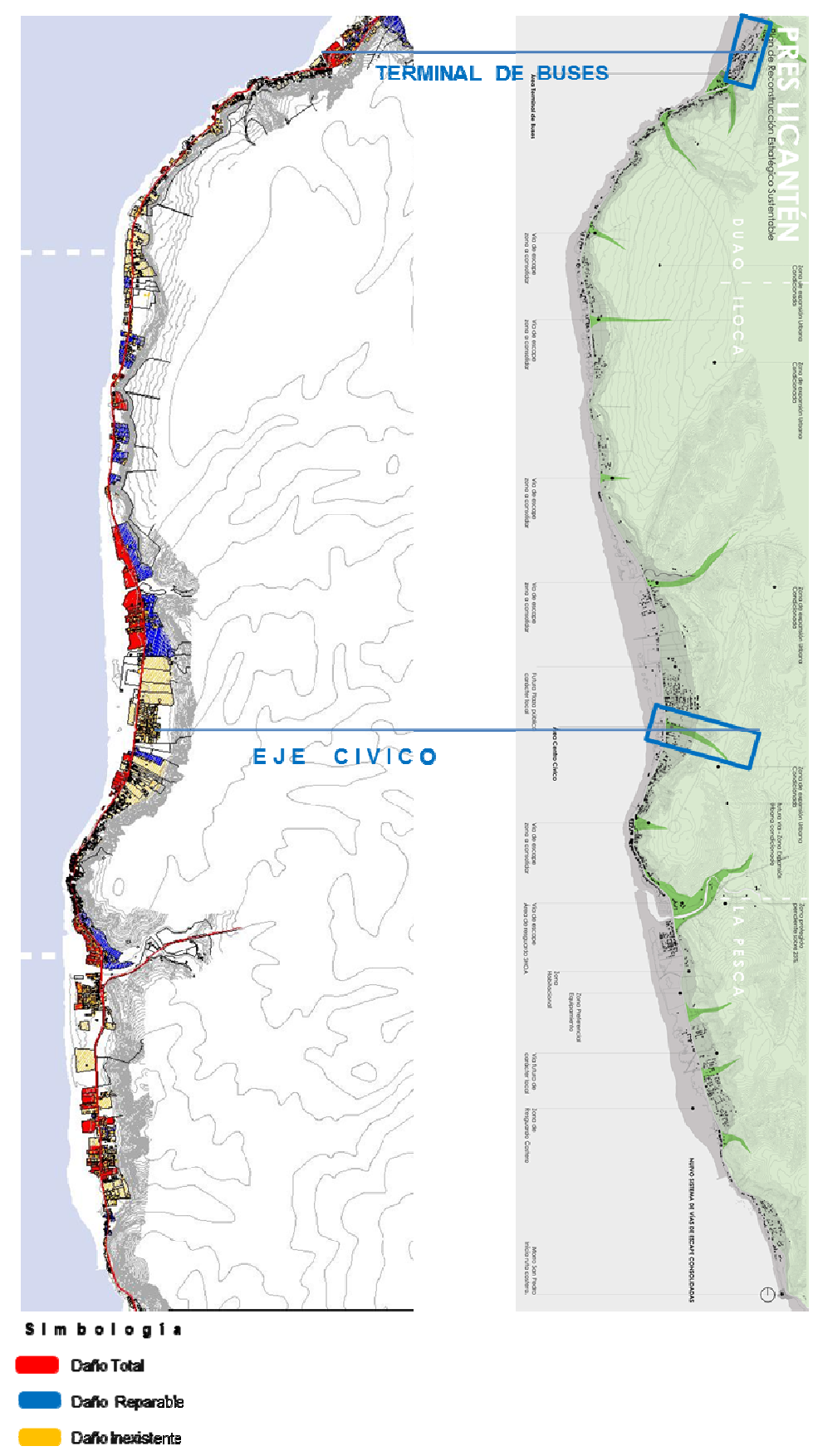

Fig. 8. Plano de Daños en construcciones de localidades Duao, lloca y La Pesca, contrastado con Plan Maestro PRES.

Fuente: Informe final PRES.

La limitada representatividad de la muestra en el proceso de participación ciudadana se ve reflejada en la escasa conformación de nuevas organizaciones sociales con posterioridad al 27-F, dominando los comités habitacionales, quienes han debido enfrentar diferentes problemas internos desde su constitución, además de intervenciones institucionales que han intentado fomentar las relaciones sociales y crear nuevas fuentes de empleo, pero lamen- 
Innovación e Investigación en Arquitectura y Territorio. Departamento de Expresión Gráfica y Cartografía.

Arquitectura. Escuela Politécnica Superior. Universidad de Alicante. №3 julio 2015

ISSN: 2341-0515

tablemente no han contado con una etapa de acompañamiento adecuada. En consecuencia el período de vida de la organización es igual al de intervención, no proyectándose en el tiempo y por tanto continúa la dinámica social histórica.

\subsubsection{Efectos sobre dimensión socio - política}

El 27-F y las siguientes etapas de reconstrucción a nivel estatal y a nivel local han generado un proceso de ajustes y cambios desde la perspectiva de la gestión social y política, no siendo Duao, lloca y La Pesca una excepción a este fenómeno reciente.

En consecuencia, la estrategia adoptada por el municipio de Licantén para afrontar el proceso está fuertemente relacionada con la gestión empresarial, que a través de aportes materiales, económicos y financiando el trabajo de horas/hombre, vinculados con la elaboración de proyectos de Reconstrucción, han tenido acceso directo a los departamentos municipales, que no contaban con el personal que requería tal desafío, en tanto, han logrado interiorizarse y posicionarse como actor relevante en las decisiones locales de índole urbana, proponiendo zonificaciones del suelo, programas arquitectónicos, nidos productivos y económicos. Aspectos que vistos por separado sólo son elementos que componen la ciudad, pero que desde la perspectiva del Hábitat Residencial son fundamentales para constituir la red de relaciones inter escalares que definen las características donde se desarrolla la vida de los habitantes. En consecuencia, lo que se encuentra actuando sobre el territorio PRES son los resultados de la gestión política que ha establecido y dirigido la intervención empresarial sobre el territorio de Duao, lloca y La Pesca durante el transcurso de los últimos cuatro años.

\subsubsection{Efectos sobre Dimensión Territorio - Medio Ambiental}

De acuerdo a lo que se ha planteado previamente resulta fundamental construir un mapeo de la intervención pública en las localidades de estudio para entender los efectos físicos del PRES sobre el territorio y así hacer visible su distribución, los montos asociados y las comunidades a las que se encuentra afectando de manera directa.

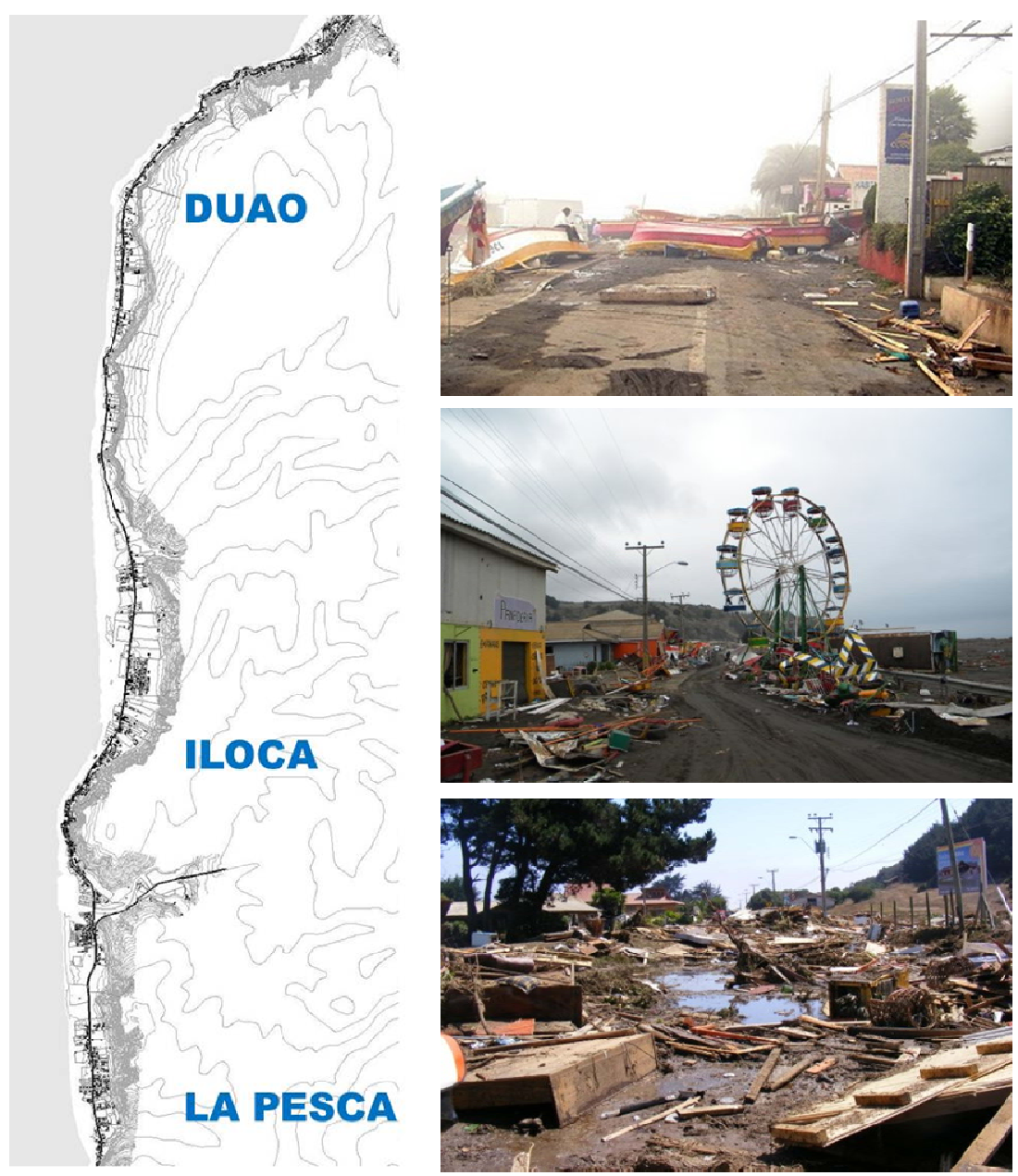

Modelo de gestión territorial utilizado en el proceso de reconstrucción post terremoto y tsunami del 27-F en Chile. Luis Eduardo González González. DOI 10.14198/i2.2015.04 
Innovación e Investigación en Arquitectura y Territorio. Departamento de Expresión Gráfica y Cartografía. Arquitectura. Escuela Politécnica Superior. Universidad de Alicante. №3 julio 2015

Fig. 9. Representación de daños en las localidades luego del 27-F. Fuente: Archivo personal 2010

Por tal motivo, a continuación se grafican los proyectos, montos asociados (expresados en pesos chilenos) y fuente de financiamiento de todas las iniciativas públicas y privadas (sólo las de gran escala), construidas, aceptadas y recibidas para el período que incluyen las cuentas públicas municipales de los años 2010 y 2011 , las cuales marcan la tendencia de desarrollo. Es necesario señalar que en este artículo no se incluye información actualizada al año 2014, ya que los principales avances de obras en los últimos dos años se han centrado en la construcción de viviendas de interés social.

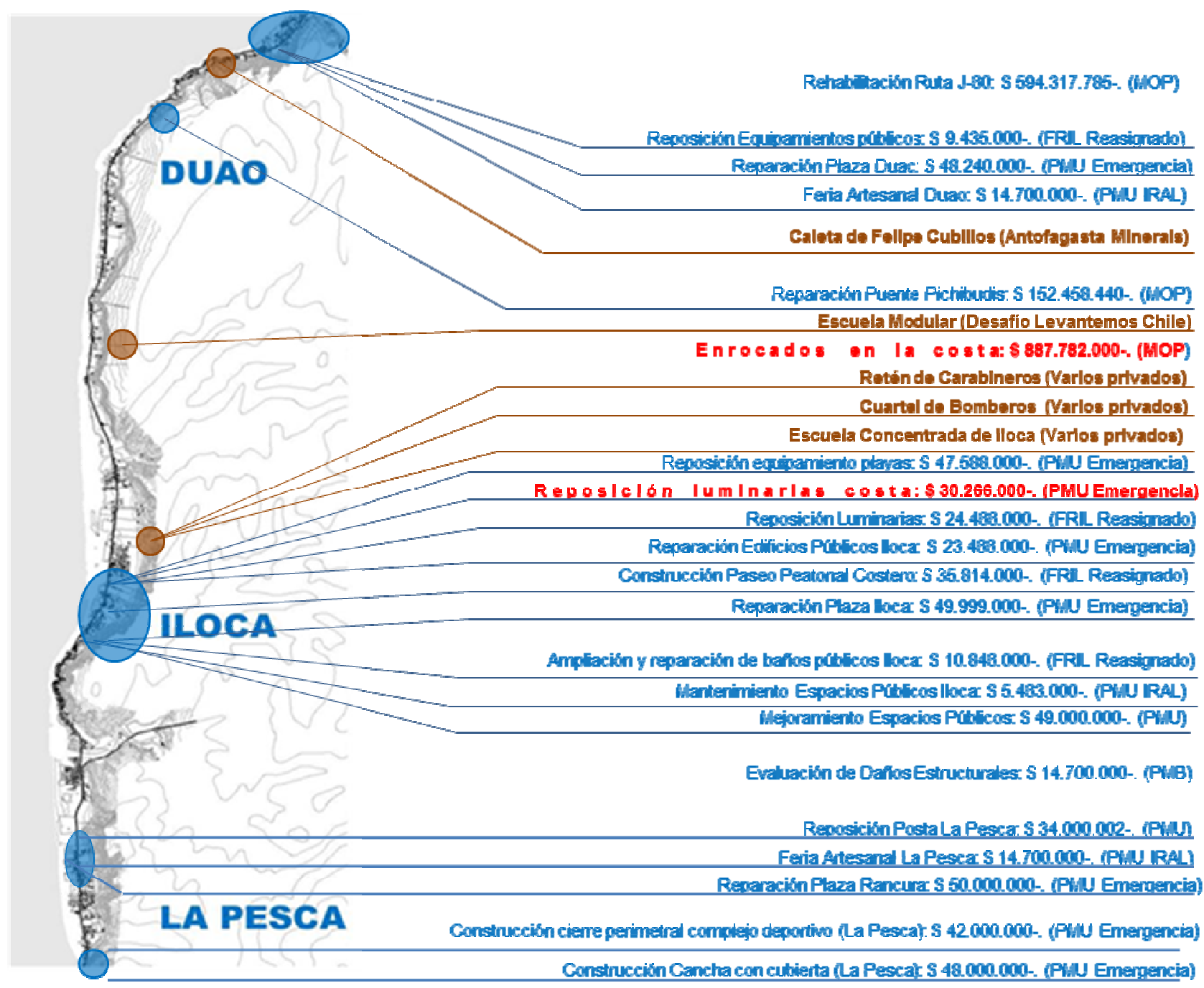

S I m bologia

Proyecto financiado por entidades públicas

Propecto financiado por entidades privadas

Propecto asociado al corwerio P.RES.

Fig. 10. Mapeo de proyectos construidos, aceptados y recibidos en Duao, lloca y La Pesca, durante los años 2010 y 2011.

Fuente: Elaboración propia en base complementados con información pública del Gobierno Local.

La figura anterior muestra las principales obras ejecutadas y que inciden directamente en las comunidades aludidas. Estas obras en un 92,31\% no forman parte de la cartera de proyectos PRES, sin embargo al ser obras ejecutadas repercuten en los tejidos sociales del lugar, donde la primera observación es que el 46,15\% de los proyectos se concentran en el área centro histórico de lloca, zona con el mayor potencial turístico de estas comuni-

Modelo de gestión territorial utilizado en el proceso de reconstrucción post terremoto y tsunami del 27-F en 15 Chile. Luis Eduardo González González. DOI 10.14198/i2.2015.04 
Innovación e Investigación en Arquitectura y Territorio. Departamento de Expresión Gráfica y Cartografía. Arquitectura. Escuela Politécnica Superior. Universidad de Alicante. №3 julio 2015

dades, y además donde se encuentra la mayor actividad económica de temporada y por tanto los mayores ingresos al municipio por conceptos de patentes comerciales, estacionamientos, partes vehiculares y comerciales, entre otros. Por lo tanto ha sido una zona a la que se potenció su crecimiento y desarrollo, donde se corrobora el sentir de las comunidades de La Pesca y Rancura, que son las zonas con menor cantidad de proyectos ejecutados y los ya existentes se han focalizado en el turista como público objetivo en desmedro del habitante local, quien debe buscar otras fuentes de ingresos para mejorar sus condiciones de vida.

\section{Conclusiones}

En Chile, a consecuencia del 27-F se hizo evidente que el país no cuenta con protocolos y/o herramientas que le permitan enfrentar un proceso de reconstrucción a escala territorial de manera adecuada, ya que solamente cuenta con medidas de tipo "viviendistas", cuyo objetivo principal es disminuir el déficit cuantitativo de viviendas ocasionado por la catástrofe.

De esta manera, en las iniciativas de reconstrucción territorial se observa una lógica de producto, el cual satisface demandas de inversión latentes, siendo posible sostenerlo a partir de las siguientes observaciones:

En primer lugar, los planes maestros de reconstrucción en sus diversas tipologías nacieron como un producto necesario y que en el contexto del modelo político - económico vigente en Chile permitió a los actores privados incidir en forma mayoritaria sobre las dinámicas sociales del territorio. La principal fuente de atracción para los proyectos arquitectónicos está dada por la rentabilidad económica y son los actores privados quienes tienen cada vez mayor participación en el proceso de elaboración de las políticas públicas de escala local. Proceso al cual se ha denominado privatización del planeamiento territorial y que ha condicionado el desarrollo de los tejidos sociales.

En segundo lugar, la condicionalidad sobre los tejidos sociales está dada por una forma actualizada de gestionar y planificar el territorio, donde el marco de acción establecido por el Estado chileno permite experimentar nuevos procesos de asociatividad y abordaje del problema desde una lógica de laboratorio urbano, donde los datos indican que la dispersión geográfica de los asentamientos, la escala de éstos y un bloque de inversores privados interesados en características específicas de dichos poblados se arriesgaron a participar en el proceso de reconstrucción, muchas veces buscando dar un beneficio a la comunidad, pero también buscando encontrar allí una oportunidad de inversión.

En tercer y último lugar, se observa en el producto denominado plan maestro una falta de validez legal frente a los organismos idóneos de las distintas escalas del territorio, es decir, Gobierno Local, Secretarías Regionales del Ministerio de Vivienda y Urbanismo, además de Gobiernos Regionales, dado que su formulación y desarrollo no tienen asidero en las normas legales que rigen la materia.

De este modo, si ponemos en relación las iniciativas de reconstrucción territorial desarrolladas en el país con el concepto Hábitat Residencial resulta posible sostener que ha tenido una baja relevancia para las dinámicas implícitas en dicho concepto, ya que no ha logrado implementar a cabalidad su cartera de obras de edificación. No obstante y por causas circunstanciales, sí ha logrado generar redes entre actores que se involucran en el territorio para intervenir desde la particularidad de sus áreas de competencia.

Durante el proceso de reconstrucción post 27-F, sólo es posible reconocer un pequeño aporte a la planificación urbana del país, proponiendo una nueva forma de problematizar los temas del territorio en base a la cohesión de diferentes actores para así construir una intervención en bloque sobre cada uno de los diferentes asentamientos afectados por la catástrofe.

En consecuencia, si bien los Planes de Reconstrucción Estratégico Sustentable son un producto que aún no logra instalarse cabalmente en el territorio como propuesta unitaria de carácter urbana, paradojalmente debido a su naturaleza experimental ha logrado que tangencialmente instituciones de ayuda social se inserten en muchas localidades que hasta antes del 27-F eran totalmente desconocidas en el país y postergadas por las políticas públicas nacionales.

Por otra parte, los Planes de Reconstrucción Estratégico Sustentables para lograr desarrollarse han necesitado de instituciones anclas (empresas mineras y educacionales) al interior de su mapa de actores, otorgándole estos un carácter altamente ejecutivo al modelo de gestión. Es decir, con la incorporación de actores privados al proceso de reconstrucción chileno, el Estado ha tendido a priorizar el cumplimiento de metas cuantitativas por sobre los reales intereses y necesidades de los damnificados por el 27-F. 
Innovación e Investigación en Arquitectura y Territorio. Departamento de Expresión Gráfica y Cartografía. Arquitectura. Escuela Politécnica Superior. Universidad de Alicante. №3 julio 2015

ISSN: 2341-0515

\section{Bibliografía}

Libro

CASTELLS, Manuel. Problemas de Investigación en Sociología Urbana. Primera Edición. Buenos Aires, Siglo Veintiuno Editores S.A. 1971. 278 p. ISBN: 978-84-323-0040-0

DERRIDA, Jacques. De la Grammatologie. Primera Edición Americana, Baltimore, USA. Johns Hopkins Paperbacks. 1976. 410p. ISBN o-8008-5830-5

KLEIN, Naomi. La doctrina del shock: El auge del capitalismo del desastre. Segunda Edición. Barcelona, Paidos Ibérica, 2010. 702 p. ISBN: 978-844-932-041-5

MOULIAN, Tomás. Chile Actual Anatomía de un Mito. Primera Edición. Santiago de Chile. LOM Ediciones. 1997. 386 p. ISBN: 956-282-432-2

OBSERVATORIO DE LA RECONSTRUCCIÓN, Reconstrucciones Sociedad Civil: Experiencias de reconstrucción en Chile post 27-F desde la sociedad civil. Primera Edición. Santiago de Chile. 2011. 159 p.

Artículos de una Publicación Seriada

AUDEFROY, Joel. La problemática de los desastres en el hábitat urbano en América Latina. Revista INVI. 2003. vol 18. Núm. 47. p. $52-71$

ARENAS, Federico. LAGOS, Marcelo. HIDALGO, Rodrigo. Los Riesgos Naturales en la Planificación territorial. TEMAS DE LA AGENDA PÚBLICA. 2010. Núm. 39. p. 1-11.

SASSEN, Saskia. Ciudades en la economía global, enfoques teóricos y metodológicos. Revista EURE. 1998. Vol. 24. Núm. 71. P. 1-50.

TAPIA. Ricardo. Vivienda y Emergencia ante desastres naturales producidos por Sismos. Sismo de 1997 en la comuna de Punitaqui, Chile. Revista INVI. 2003. Vol. 18. Núm. 47. P. 89-103.

Normas

MINISTERIO DE VIVIENDA Y URBANISMO. Convenio de Cooperación Plan de Reconstrucción Estratégico Sustentable de Duao, lloca y La Pesca. MINVU. Santiago de Chile: MINVU, 2010.

Tesis No Publicadas

GONZÁLEZ, Luis Eduardo. "Plan de Reconstrucción Estratégico Sustentable de Duao, lloca y La Pesca: Deconstrucción de una iniciativa de reconstrucción post 27-F, Implicancias sobre el Hábitat Residencial". Director: Walter Imilan. Clase de tesis: Master en Hábitat Residencial. Universidad de Chile, Santiago de Chile, 2013.

Informes

Informes publicados:

GOBIERNO DE CHILE. Programa Chile unido reconstruye mejor. MINVU. Santiago de Chile, 2010. 110 p.

GOBIERNO DE CHILE. Programa Chile unido reconstruye mejor. MINVU. Santiago de Chile, 2011. 110 p.

IMILAN, Walter. GONZÁLEZ, Luis Eduardo. Ánalisis comparativo de planes maestros de reconstrucción territorial: Estado de Avance al mes de julio de 2013. Ciudadanía y territorio. Observatorio de Vivienda y Políticas Públicas. Santiago de Chile, 2013. $34 \mathrm{p}$.

LARRAGAÑA, Osvaldo; HERRERA,Rodrigo. Encuesta Post Terremoto: Principales Resultados. Efectos en la calidad de vida de la población afectada por el terremoto/tsunami. Ministerio de Desarrollo Social. Santiago de Chile, 2010. 33 p.

SCHUSCHNY, Andrés. SOTO, Humberto. Guía metodológica. Diseño de indicadores compuestos de desarrollo sostenible, Chile. CEPAL. Santiago de Chile, 2009. 109 p.

Informes inéditos:

INFRACON. “Actualización estudio Plan Regulador Comunal de Licantén”, Informe inédito. MINVU. 2009. 
Innovación e Investigación en Arquitectura y Territorio. Departamento de Expresión Gráfica y Cartografía. Arquitectura. Escuela Politécnica Superior. Universidad de Alicante. №3 julio 2015

\section{Documentos Audiovisuales}

Grabaciones:

ALLARD, Pablo. Entrevista a Pablo Allard realizada por Plataforma Urbana. Santiago de Chile, 2010.

IACOBELLI, Andrés. Entrevista a Andrés lacobelli realizada por HATCH. Santiago de Chile, 2010.

MATTE, Magdalena. Entrevista a Magdalena Matte realizada por HATCH. Santiago de Chile, 2010.

POLIDURA, Antonio. Entrevista a Antonio Polidura realizada por Luis Eduardo González. Santiago de Chile, 2012. 


\section{Biografía}

Luis Eduardo González Arquitecto chileno (Universidad de Valparaíso, 2008), Magíster en Hábitat Residencial (Universidad de Chile, 2013). Co - Investigador en Observatorio de la Reconstrucción de la Universidad de Chile, Coordinador de la Sesión "Sustainable Development in Emergency Context" en ENCUENTROS 2015 (ChileGlobal) la cual se desarrollará en el mes de Julio en la ciudad de Rotterdam, Holanda.

Ha escrito diversos artículos sobre el procesos de reconstrucción urbana y territorial en contextos post - desastre natural desde la perspectiva del Hábitat Residencial, es decir, realizando un análisis de las dimensiones socio políticas, socio - económicas y territoriales.

Sus líneas de investigación son el diseño urbano, geografía urbana y la arquitectura desde una perspectiva fenomenológica.

Luis Eduardo González is a Chilean architect (University of Valparaiso, 2008), Master in Residential Habitat (University of Chile, 2013). Co-Investigator in Reconstruction Observatory in University of Chile, also he is Coordinator of "Sustainable Development in Emergency Context Session" in ENCUENTROS 2015 (Chile Global). This Seminar going to happen in early July in Rotterdam City, Netherland.

He has written several papers about urban reconstruction process in natural disaster context, this from the residential habitat perspective, that is to say, he analyzes the socio - political, socio - economic and territorial aspects.

His research interests are urban design, urban geography and the architecture from the phenomenology perspective. 